\title{
Erratum to: Endoscopic ultrasound-guided fine needle aspiration improves the pre-operative diagnostic yield of solid-pseudopapillary neoplasm of the pancreas: an international multicenter case series (with video)
}

\author{
Joanna K. Law $\cdot$ Alina Stoita $\cdot$ Wallia Wever $\cdot$ Ferga C. Gleeson \\ Andrew M. Dries • Amanda Blackford • Vandhana Kiswani • Eun Ji Shin • \\ Mouen A. Khashab - Marcia Irene Canto • Vikesh K. Singh • Anne Marie Lennon \\ Published online: 10 July 2014 \\ (C) Springer Science+Business Media New York 2014
}

Erratum to: Surg Endose

DOI 10.1007/s00464-014-3508-8

The correct spelling of the third author is Wallia Wever.

The online version of the original article can be found under doi:10. 1007/s00464-014-3508-8.

J. K. Law $(\varangle) \cdot$ V. Kiswani · E. J. Shin ·

M. A. Khashab - M. I. Canto - V. K. Singh · A. M. Lennon Division of Gastroenterology and Hepatology, The Sol Goldman Pancreatic Cancer Research Center, The Johns Hopkins Medical Institutions, 1800 Orleans St, Suite 7125 J, Baltimore,

MD 21205, USA

e-mail: jlaw8@jhmi.edu
A. Stoita
Department of Gastroenterology, St. Vincent's Hospital, Sydney,
NSW, Australia
W. Wever
Unidad de Exploraciones Digestivas, IMLF, Caracas, Venezuela
F. C. Gleeson
Division of Gastroenterology, Mayo Clinic College of Medicine, Rochester, MN, USA
A. M. Dries
Division of Gastroenterology, Carolinas Medical Center,
Charlotte, NC, USA
A. Blackford
Department of Oncology, Sidney Kimmel Comprehensive Cancer Center, The Johns Hopkins Medical Institutions, Baltimore, MD, USA

